\title{
Unusual Presentation of a Gangrenous Cholecystitis that Mimics a Bowel Perforation
}

\author{
Occhionorelli $S^{1}$, Stano $\mathbf{R}^{2}$, Bonazza $S^{1}$, Morganti $\mathrm{L}^{1 *}$, Andreotti $\mathrm{D}^{\mathbf{1}}$, Cappellari $\mathrm{L}^{2}$ and VasquezG ${ }^{2}$ \\ ${ }^{1}$ Department of Morphology, Surgery and Experimental Medicine, University of Ferrara, Via Luigi Borsari 46-Ferrara, Italy \\ ${ }^{2}$ Department of Surgery-Emergency Surgery Service, Via A. Moro 8, 44100, Ferrara ER, Italy
}

Received: March 14, 2014; Accepted: August 07, 2014; Published: September 26, 2014

*Corresponding author: Morganti Lucia, Department of Morphology, Surgery and Experimental Medicine, University of Ferrara, Via Luigi Borsari 46-Ferrara, Italy, E-mail: lucymorg@hotmail.it

\begin{abstract}
We report the case of a diabetic 49-year-old man affected by phlegmonous cholecystitis with an unusual radiological presentation mimicking a bowel perforation. Actually, abdomen X-ray showed free intraperitoneal air spots (dark crescent beneath the diaphragm) in the upright positions. We have not found any similar cases in the published literature, except for a case report about an unusual presentation of an emphysematous cholecystitis. The clinical practitioner has to pay attention not to fall into a fixation error during diagnosis.
\end{abstract}

\section{Abbreviations}

US:Ultrasound; BMI: Body Mass Index; ER: Emergency Room; PT: Prothrombin Time; INR: International Normalized Ratio; APTT: Activated Partial Thromboplastin Time; CT: Computed Tomography; PDS: Polydioxanone(suture); UI: International Unit

\section{Introduction}

Gangrenous cholecystitis is a severe gallbladder infection, which occurs approximately in $1 \%$ of acute cholecystitis. This condition is characterized by the presence of gas in the gallbladder lumen, as well as in its wall or nearby tissues, without abnormal communication among the digestive and biliary ducts [1]. This infection is caused by gas-producing organisms (Escherichia coli, Clostridium perfringens, Bacteroides fragilis) and complications include hepatic abscess formation, biliary sepsis and hepatorenal failure [2]. Abdominal X-ray and abdominal Ultra Sound (US) scan [3] are the first modality to detect gallbladder infection and might demonstrate the presence of air inside the gallbladder wall or lumen, in nearby tissues or in the biliary ducts.

Additionally, an abdominal Computed Tomography (CT) scan might be useful to identify possible gallstones in biliary ducts, irregularity or thickening of the gallbladder wall, presence of intraluminal or mural air, presence of pericholecystic fluid, extension of the inflammatory process to hepatic parenchyma $[4,5]$. Surgical intervention is usually the procedure of choice in phlegmonous and gangrenous cholecystitis (partial or total cholecystectomy). A less invasive approach (i.e. percutaneous transhepatic gallbladder drainage under US guidance) can be effective before a phlegmonous cholecystitis becomes gangrenous.

\section{Case Report}

A male patient aged 49 years, obese (Body Mass Index $(B M I)=52.24)$, affected by Type II diabetes was presented to Emergency Room (ER) with a complaint of strong upper abdominal quadrants pain, without other associated symptoms. Approximately 7 days before, he had a similar pain associated with high fever and vomiting, which withdrew with antibiotic treatment (moxifloxacin). On physical examination, the abdomen was diffusely tender, despite treatment with opioids. Moreover, the patient showed blood hypertension (200/100 mm Hg) and tachycardia. Laboratory investigations revealed leucocytosis (white blood cells $17.58 \times 10^{3} /$ microL, neutrophil $12.36 \times 10^{3}$ / microL), mild alteration of coagulation (Prothrombin Time (PT) 1.37 International Normalized Ratio (INR) , fibrinogen 946 $\mathrm{mg} / \mathrm{dl}$, Activated Partial Thromboplastin Time (APTT) ratio 1.33), hyperglycemia $232 \mathrm{mg} / \mathrm{dl}$. In addition, he showed light hyperbilirubinemia (total bilirubin $1.77 \mathrm{mg} / \mathrm{dl}$, direct bilirubin $1.30 \mathrm{mg} / \mathrm{dl}$ ), mild electrolyte disturbance (Na $134 \mathrm{mEq} / \mathrm{L}, \mathrm{Cl} 96$ $\mathrm{mEq} / \mathrm{L}$ ), hyperamylasemia $180 \mathrm{U} / \mathrm{l}$ and the level of C-reactive protein was $16.47 \mathrm{mg} / \mathrm{dl}$. Abdominal X-ray revealed a dark crescent beneath the diaphragm, as a bowel/gastric perforation (Figure 1). Because the clinical condition of the patient was quickly worsening and diagnosis seemed fairly clear, a CT scan was not performed and the patient was brought to the operating room, without further investigations.

An exploratory laparotomy was performed. The operation showed diffuse peritonitis and presence of purulent liquid in all the abdominal recess, without macroscopic intestinal or gastric perforations. The gallbladder had no signs of perforation but was affected by an advance inflammatory process, which led to emphysema with gangrene.Moreover, the gallbladder appeared non detachable from the duodenum and the liver. An anterograde subtotal cholecystectomy with infundibular closure through running Polydioxanone Suture ((PDS) 3/0) was performed, after gallstones were removed. A more careful exploration of the abdominal organs and the test with methylene blue through 

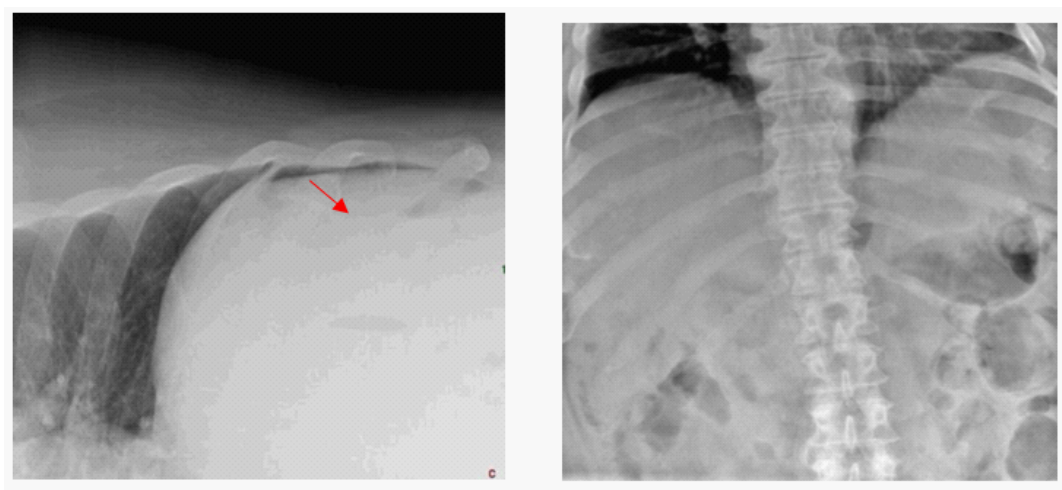

Figure 1: Dark crescent beneath the diaphragm.

nasogastric tube did not prove visceral perforations. Bacterial culture of the bile showed the presence of Escherichia coli. The patient only stayed 48 hours in intensive unit care. In our ward, the hospital stay of the patient was without any complications, except for a mild anemia (haemoglobin $7.6 \mathrm{~g} / \mathrm{dl}$ ) resolved with blood transfusions (3 International Unit (U.I)). Infection was treated with antibiotic (ciprofloxacin) for 25 days. As the patient had no more fever and pain was under control; he was discharged on the twelfth postoperative day.

\section{Discussion}

In literature, there are few other cases of emphysematous/ gangrenous cholecystitis presented with pneumoperitoneum [6,7]. These patients have some common features: diabetes, upper quadrant abdominal pain (right more than left, and not necessarily with fever), leucocytosis, lithiasic gallbladder and specific bacterial isolation (E. coli, C. perfringens or B. fragilis). Anaerobic organisms grow easily in gallbladder with vascular insufficiency of the wall and alkaline bile, as occurs in cholecystitis. The excessive distension of the gallbladder wall can result into a leakage of gas through the intact mucosa, with the gas spreading into the perimuscular layers and collecting under the serosa and into the peritoneal cavity [8]. Gangrenous cholecystitis is a life-threatening condition, which can require one- or two-step early surgical intervention [9]. Fixation errors could easily happen. Free intraperitoneal gas detected by radiological investigations, could be a suspected cause, but not a conclusive diagnosis for organ perforation. If the patient is stable and has plenty of comorbidity, it is preferable to proceed with further radiological investigations (i.e. abdominal CT scan) in order to make a more careful differential diagnosis [10]. Actually, Advanced gallbladder inflammations and infections in some critical patients, can be managed effectively by a twostep approach; wherein a minimally invasive ultrasound guided drainage, is followed by cholecystectomy $[11,12]$. Because of a lack of evidence from randomized trials $[13,14]$, it remains unclear if acute cholecystitis treatment, would benefit more from the routine use of cholecystostomy as a unique treatment, or using it as a bridge to laparoscopic or laparotomic surgery. There is a need for a clear diagnosis and a clinical stabilization $[11,12]$ to allow more in-depth diagnostic work. In our case, this was not possible for two reasons: (a) poor conditions of the patient and (b) the diagnostics addressed to a perforation of a hollow organ. In addition, at the time of the intervention, the patient showed a gangrenous cholecystitis case, with no indications for cholecystostomy.

\section{Conclusion}

Gangrenous cholecystitis represents a life-threatening condition, which requires a surgical procedure in emergency setting. A large gas production is unusual but it might occur: this can lead to a wrong diagnosis but the clinical conditions of the patient, however, require an urgent surgical procedure. Regarding the possibility of treating acute cholecystitis by ultrasound-guided drainage, there is an ongoing debate that must define which cases must be treated and in which way.

\section{References}

1. Aurajo DB, Renck DV, Britto M AP, Oliveira DS, Lauremann FT. Emphysematous cholecystitis: An unusual presentation of a rare disease. MJM. 2004; 8: 28-30.

2. Charalambous C, Malik RA, Mamtora H, Aslam R, Young RJ. Sub-acute presentation of emphysematous cholecystitits in a type 2 diabetic patient. Int J Diabetes \& Metabolism. 2000; 8(3).s

3. Sunnapwar A, Raut AA, Nagar AM, Katre R. Emphysematous cholecystitis: imaging findings in nine patients. Indian J radiol Imaging. 2011; 21(2): 142-146. doi: 10.4103/0971-3026.82300.

4. Gill KS, Chapman HA, Weston MJ. Changing face of emphysematous cholecystitis. Br J Radiol 1997; 70(838): 986-991.

5. Grayson DE, Abbott RM, Levy AD, Sheman PM. Emphysematous infections of the abdomen and pelvis: a pictorial review. Radiographics. 2002; 22(3): 543-561.

6. Radin DR, Hall JM. Emphysematous cholecystitis presenting with pneumoperitoneum. Am J Roentgenology. 1987; 149: 1175-1176.

7. Watson DI, Isaacs J, Williams RS. Emphysematous Cholecystitis can cause pneumoperitoneum. Aust NZJ Surg 1994; 64(2): 130-131.

8. Konno K, Ishida H, Naganuma H, Sato M, Komatsuda T, Sato A, et al. Emphysematous Cholecystitis: Sonographic findings. Abdom Imaging 2002; 27(2): 191-195.

9. Adani GL, Marcello D, Carrella G, Maestroni U, Sanna A, Cataldi A, et al. Approccio diagnostico e terapeutico nell'ileo biliare. Chirurgia. 2000; 13(5-6): 285-288. 
10. Cervi PM, L Cappellari, P Cardona, L Bonari, F Zucchi, G Balboni. La colecistite enfisematosa. Descrizione di un caso. La radiologia medica 1990; 80: 102

11. Sipra MR, Nissan A, Zamir O, Cohen T, Fields SI, Freund HR. Percutaneous transhepatic cholecystostomy and delayed laparoscopic cholecistectomy in critically ill patients with acute calculus cholecystitis. Am J Surg 2002;183(1): 62-66.

12. Little MW, Briggs JH, Tapping CR, Bratby MJ, Anthony s, Phillips-Huges J, et al. Percutaneous cholecystostomy: The radiologist's role. Clinical
Radiology 2013; 68 (7): 654-660. doi: 10.1016/j.crad.2013.01.017.

13. Winbladh A, Gullstrand P, Svanvik J, Sandstrom P. Systematic review of cholecystostomy as a treatment option in acute cholecystitis. HPB 2009; 11(3): 183-193.

14. Rodriguez-Sanjuan JC, Arruabarrena A, Sanchez-Moreno L, GonzalezSanchez F, Herrera LA, Gomez-Fleitas M. Acute cholecistitis in high surgical risk patients: percutaneous cholecystostomy or emergency cholecystectomy? Am J Surg 2012; 204 (1): 54-59. doi: 10.1016/j. amjsurg.2011.05.013. 